\title{
Validated Spectrophotometric Methods for the Determination of Mycophenolate: An Anti-Neoplastic Agent in Bulk and Pharmaceutical Dosage Forms
}

\author{
A. Narendra, ${ }^{1}$ D. Deepika, ${ }^{2}$ and M. Mathrusri Annapurna ${ }^{3}$ \\ ${ }^{1}$ Department of Pharmaceutical Analysis and Quality Assurance, Roland Institute of Pharmaceutical Sciences, \\ Berhampur 760010, India \\ ${ }^{2}$ Department of Pharmaceutical Analysis and Quality Assurance, Royal College of Pharmacy and Health Sciences, \\ Berhampur 760002, India \\ ${ }^{3}$ Department of Pharmaceutical Analysis and Quality Assurance, GITAM Institute of Pharmacy, GITAM University, \\ Visakhapatnam 530045, India \\ Correspondence should be addressed to A. Narendra; naren_angirekula@yahoo.com
}

Received 28 November 2011; Revised 16 May 2012; Accepted 17 May 2012

Academic Editor: Irene Panderi

Copyright (c) 2013 A. Narendra et al. This is an open access article distributed under the Creative Commons Attribution License, which permits unrestricted use, distribution, and reproduction in any medium, provided the original work is properly cited.

\begin{abstract}
Three simple, precise and cost-effective spectrophotometric methods have been developed for the determination of Mycophenolate in bulk and its pharmaceutical formulations. Mycophenolate shows $\lambda_{\max }$ at $250.0 \mathrm{~nm}$ in zero-derivative spectrum (method A), $258.0 \mathrm{~nm}$ in first-derivative spectrum (method B) and method C is based on the calculation of area under curve (AUC) for analysis of Mycophenolate in the wavelength range of $240.0-260.0 \mathrm{~nm}$. The drug follows the Beer-Lambert's law in the concentration range of $1.0-150.0 \mu \mathrm{g} / \mathrm{mL}$ for all the methods. The methods were validated by following the analytical performance parameters suggested by the International Conference on Harmonization. All validation parameters were within the acceptable range. The developed methods were successfully applied to estimate the amount of Mycophenolate in bulk and pharmaceutical dosage forms.
\end{abstract}

\section{Introduction}

Mycophenolate (MPH) chemically, 2-(morpholin-4-yl)ethyl (4E)-6-(4-hydroxy-6-methoxy7-methyl-3-oxo-1,3-dihydro2-benzofuran-5-yl)-4-methyl hex-4enoate (Figure 1). Mycophenolate mofetil is the 2-morpholino ethyl ester of mycophenolic acid (MPA), an immunosuppressive agent, inosine monophosphate dehydrogenase (IMPDH) inhibitor. It is a potent, selective, uncompetitive, and reversible inhibitor of inosine mono phosphate dehydrogenase and therefore inhibits the de novo pathway of guanosine nucleotide synthesis without incorporation into DNA. Since T- and B-lymphocytes are critically dependent for their proliferation on de novo synthesis of purines, whereas other cell types can utilize salvage pathways, it has potent cytostatic effects on lymphocytes. It inhibits proliferative responses of T- and B-lymphocytes to both mitogenic and allospecific stimulation. Addition of guanosine or deoxyguanosine reverses the cytostatic effects of mycophenolic acid on lymphocytes. Mycophenolic acid also suppresses antibody formation by B-lymphocytes and prevents the glycosylation of lymphocyte and monocyte glycoproteins that are involved in intercellular adhesion to endothelial cells and may inhibit recruitment of leukocytes into sites of inflammation and graft rejection.

The different analytical methods that are reported for its determination include HPLC [1-14], LC/MS [15], HPTLC [16], spectrophotometry [17], and gas chromatography [18]. The aim of the present work is to develop and validate for the estimation of Mycophenolate in bulk and pharmaceutical formulations by derivative spectrophotometry [19] and to validate as per the ICH guidelines [20]. Very few methods are available for the determination of Mycophenolate using spectrophotometry, which is very sensitive and o costeffective. The present proposed method was developed using $0.02 \mathrm{M}$ Octane 1-sulfonic acid buffer solution and validated. 
<smiles>COc1c(C)c2c(c(O)c1C/C=C(\C)CCC(=O)OCCN1CCOCC1)C(=O)OC2</smiles>

FIgURE 1: Chemical structure of Mycophenolate.

\section{Experimental}

2.1. Chemicals and Reagents. Mycophenolate working standard was kindly provided by Alembic Ltd., (Vadodara, India) and was used as received. A commercial formulation was purchased from the local market. Octane 1-sulphonic acid sodium salt of analytical grade solution was prepared in Milli$\mathrm{Q}$ water.

2.2. Instrumentation. A double-beam UV-VIS spectrophotometer (UV-1800, Shimadzu, Japan) connected to computer loaded with spectra manager software UV Probe was employed with spectral bandwidth of $1 \mathrm{~nm}$ and wavelength accuracy of $\pm 0.3 \mathrm{~nm}$ with a pair of $10 \mathrm{~mm}$ matched quartz cells. All weights were taken on electronic balance (Denver, Germany). For scanning, the wavelength range selected was from $400 \mathrm{~nm}$ to $200 \mathrm{~nm}$ with medium scanning speed.

2.3. Preparation of $(0.02 \mathrm{M})$ Octane 1-Sulfonic Acid Buffer Solution. 4.35 grams of octane 1-sulfonic acid was dissolved in $800 \mathrm{~mL}$ of distilled water and the $\mathrm{pH}$ was adjusted to 3.5 with $o$-phosphoric acid in a $1000 \mathrm{~mL}$ volumetric flask.

2.4. Preparation of Standard Stock Solution. The standard solution of $\mathrm{MPH}$ was prepared by dissolving accurately weighed $10 \mathrm{mg}$ of the drug in methanol and diluted to $10 \mathrm{~mL}$ with methanol to obtain a final concentration of $1000 \mu \mathrm{g} / \mathrm{mL}$. From this solution, $2.5 \mathrm{~mL}$ was taken and diluted with $0.02 \mathrm{M}$ octane 1-sulfonic acid buffer in a $25 \mathrm{~mL}$ volumetric flask to prepare a working standard solution $(100 \mu \mathrm{g} / \mathrm{mL})$.

\section{Method A}

3.1. Zero-Derivative Spectrometry. Series dilutions of standard solutions were prepared in $10 \mathrm{~mL}$ volumetric flasks and diluting to volume with $0.02 \mathrm{M}$ Octane 1 -sulfonic acid buffer $(\mathrm{pH} 3.5 \pm 0.05)$ to produce the concentrations ranging from $1.0-150.0 \mu \mathrm{g} / \mathrm{mL}$. The above solutions were scanned over the range of $400 \mathrm{~nm}$ to $200 \mathrm{~nm}$ against blank. The $\lambda_{\max }$ was found to be at 250.0 and $305.0 \mathrm{~nm}$ (Figure 2). But the present study was carried out at $250.0 \mathrm{~nm}$ where the Beer-Lambert's law was following properly and statistical data was shown in Table 1. A calibration curve was constructed by plotting the concentration on the $x$-axis and the corresponding absorbance (at $250 \mathrm{~nm}$ ) on $y$-axis.

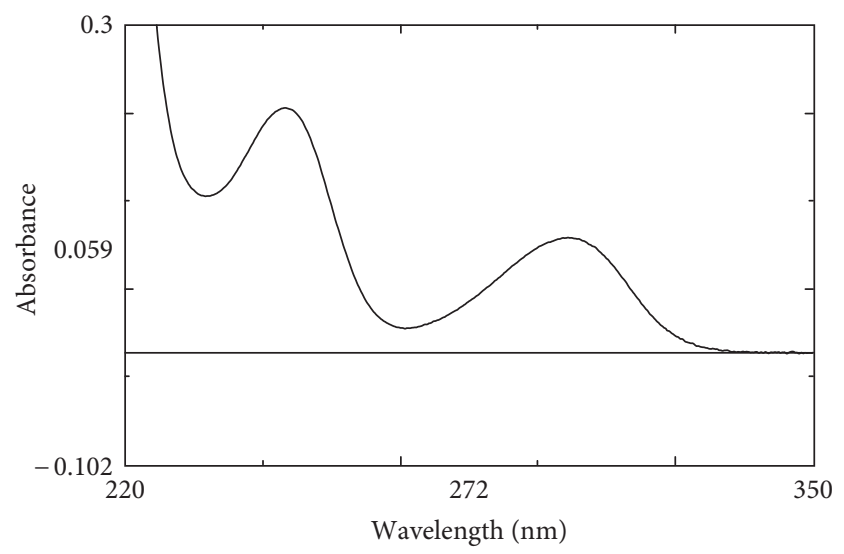

Figure 2: UV absorption spectrum of Mycophenolate $\left(D_{0}\right)$ $(10 \mu \mathrm{g} / \mathrm{mL})$.

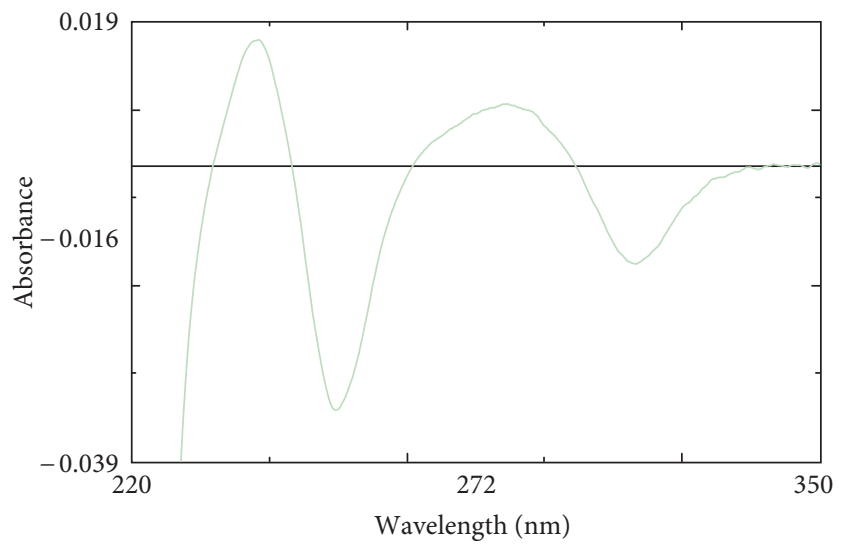

FIGURE 3: First-derivative absorption spectrum of Mycophenolate $\left(D_{1}\right)(20 \mu \mathrm{g} / \mathrm{mL})$.

\section{Method B}

4.1. First-Derivative Spectrometry. The zero-order spectrum was derivatised to get first-order derivative spectra (Figure 3) by the inbuilt spectra manager software "UV Probe." The derivative spectrum shows maxima at $258 \mathrm{~nm}$, and the derivative absorbance $(d A / d \lambda)$ was noted at $258 \mathrm{~nm}$ for all the analytical calculations [21].

A graph was drawn by taking the concentration of the drug solution on the $x$-axis and the corresponding $d A / d \lambda$ values (maxima, at $258.0 \mathrm{~nm}$ ) on the $y$-axis.

\section{Method C}

5.1. Area-Under-Curve Method. The AUC (area-undercurve) method is applicable where there is no sharp peak or when broad spectra are obtained. It involves the calculation of integrated value of absorbance with respect to the wavelength between two selected wavelengths $\lambda_{1}(240 \mathrm{~nm})$ and $\lambda_{2}(260 \mathrm{~nm})$. In method $A$ the $\lambda_{\max }$ was observed at $250 \mathrm{~nm}$, and therefore for method $\mathrm{C}$ the AUC was selected between the wavelength $240-260 \mathrm{~nm}$ (i.e., $\lambda_{\max } \pm 5$ or $10 \mathrm{~nm}$; 
TABLE 1: Optical characteristics and validation parameters of Mycophenolate.

\begin{tabular}{lccc}
\hline Parameters & Method A & Method B & Method C \\
\hline Beer-Lambert's range $(\mu \mathrm{g} / \mathrm{mL})$ & $1-150$ & $1-150$ & $1-150$ \\
$\lambda_{\max } /$ wavelength range $(\mathrm{nm})$ & 250 & $7.37 \times 10^{2}$ & $240-260$ \\
Molar absorptivity $(\mathrm{L} / \mathrm{mol} \cdot \mathrm{cm})$ & $9.71 \times 10^{2}$ & - & $4.68 \times 10^{4}$ \\
Sandell's sensitivity $(\mu \mathrm{g} \mathrm{cm} / 0.001$ absorbance unit) & 0.05 & 0.001 & 0.107 \\
Slope & 0.022 & 0.0002 & 0.0036 \\
Standard deviation of slope & 0.0252 & 0.000 & 0.025 \\
Intercept & 0.001 & 0.000 & 0.0025 \\
Standard deviation of intercept & 0.0003 & 0.999 & 0.999 \\
Correlation coefficient & 0.999 & & $0.92-1.11$ \\
Precision (RSD, \%) & & $0.78-0.90$ & $0.87-1.04$ \\
Intraday $(n=3)$ & $0.61-1.25$ & $0.66-1.12$ & $99.75-100.90(0.38)$ \\
Interday $(n=3)$ & $0.96-1.09$ & $98.56-100.54(0.41)$ \\
Accuracy $(\%$ recovery) $\%$ RSD) & $99.87-101.80(0.23)$ & & \\
\hline
\end{tabular}

TABLE 2: Assay results of Mycophenolate in pharmaceutical dosage form.

\begin{tabular}{|c|c|c|c|c|}
\hline \multirow{2}{*}{ Formulation (tablets) } & \multirow{2}{*}{ Labelled amount (mg) } & \multicolumn{3}{|c|}{ \% Recovery } \\
\hline & & Method A & Method B & Method C \\
\hline Renofix & 500 & 100.05 & 99.82 & 100.04 \\
\hline Mycept & 500 & 99.87 & 100.02 & 99.89 \\
\hline Cellcept & 500 & 99.96 & 99.97 & 99.93 \\
\hline
\end{tabular}

$\lambda_{1}$ and $\lambda_{2}=240-260 \mathrm{~nm}$ ). A graph can be plotted by taking the concentration of the drug solution on the $x$-axis and the corresponding AUC value on the $y$-axis.

\section{Method Validation}

6.1. Linearity. For all the methods, $(1.0-150.0 \mu \mathrm{g} / \mathrm{mL})$ calibration curves were prepared on three different days. The results obtained were used to calculate the equation of the line by using linear regression by the least-squares regression method.

6.2. Assay of Mycophenolate Tablets. Mycophenolate is available in the local market with different brand names in India such as Renofix (500 mg, UNICHEM Laboratories Ltd.), MYCEPT (500 mg, PANACEA Biotech Ltd.), and CELLCEPT (500 mg, ROCHE Pharmaceuticals).

Twenty tablets of Mycophenolate from three different brands were collected from pharmacy store, weighed and finely powdered. Powder equivalent to $10 \mathrm{mg}$ of the drug was transferred to a $100 \mathrm{~mL}$ volumetric flask and dissolved in about $40 \mathrm{~mL} \quad 0.02 \mathrm{M}$ octane-sulphonic acid buffer, ultra sonicated for 30 minutes, filtered through Whatman filter paper (number 41), and suitably diluted as per the requirement. The results obtained with three brands were summarised in Table 2.

6.3. Precision. The intraday and interday precision of the proposed methods was performed on the same day with three different concentration levels $(n=3)$ and on three different days at three different concentration levels $(n=3)$ of MPH $(10.0,20.0$, and $50.0 \mu \mathrm{g} / \mathrm{mL})$, and the results (\% RSD) were reported (Table 1 ).

6.4. Accuracy. This parameter was evaluated by the percent recovery studies at concentration levels of 80,100 , and $120 \%$, which consisted of adding known amounts of MPH pure drug solution to a preanalysed formulation solution. An extracted formulation solution containing Mycophenolate $(10.0 \mu \mathrm{g} / \mathrm{mL})$ was spiked with pure drug solution $(80,100$, and $120 \%$ ) in different $10 \mathrm{~mL}$ volumetric flasks, and the absorbance was measured $(18,20$, and $22 \mu \mathrm{g} / \mathrm{mL})$. The $\%$ recovery as well as the $\%$ RSD was calculated (Table 1 ).

\section{Results and Discussion}

Beer-Lambert's law was obeyed in the concentration range of $1-150 \mu \mathrm{g} / \mathrm{mL}$ for all the three methods A, B, and C. The regression equations were given in Table 1.

The $\%$ recovery from the formulation (Table 2 ) was found to be 99.87-100.05 for method A, 99.82-100.02 for method B, and 99.89-100.04 for method $C$. The proposed methods were validated as per the ICH guidelines. The \% RSD in precision and accuracy was found to be less than 2.0 indicating that the proposed methods are precise and accurate. The \% recovery was found to be within the acceptable range in all the three methods. Therefore, the present methods can be employed for the determination of Mycophenolate in pharmaceutical formulations successfully. 


\section{Conclusion}

The three validated methods can be successfully applied for the determination of Mycophenolate in tablet dosage forms. The three methods are very simple and cost-effective for the routine analysis of pharmaceutical formulations.

\section{References}

[1] H. Hosotsubo, S. Takahara, Y. Kokado et al., "Rapid and simple determination of mycophenolic acid in human plasma by ion-pair RP-LC with fluorescence detection," Journal of Pharmaceutical and Biomedical Analysis, vol. 24, no. 4, pp. 555-560, 2001.

[2] J. F. Gummert, U. Christians, M. Barten, H. Silva, and R. E. Morris, "High-performance liquid chromatographic assay with a simple extraction procedure for sensitive quantification of mycophenolic acid in rat and human plasma," Journal of Chromatography B, vol. 721, no. 2, pp. 321-326, 1999.

[3] D. Teshima, N. Kitagawa, K. Otsubo, K. Makino, Y. Itoh, and R. Oishi, "Simple determination of mycophenolic acid in human serum by column-switching high-performance liquid chromatography," Journal of Chromatography B, vol. 780, no. 1, pp. 21-26, 2002.

[4] C. G. Zambonin, A. Aresta, and F. Palmisano, "Determination of the immunosuppressant mycophenolic acid in human serum by solid-phase microextraction coupled to liquid chromatography," Journal of Chromatography B, vol. 806, no. 2, pp. 89-93, 2004.

[5] A. Pastore, A. Lo Russo, F. Piemonte, L. Mannucci, and G. Federici, "Rapid determination of mycophenolic acid in plasma by reversed-phase high-performance liquid chromatography," Journal of Chromatography B, vol. 776, no. 2, pp. 251-254, 2002.

[6] N. Sugioka, H. Odani, T. Ohata, H. Kishimoto, T. Yasumura, and K. Takada, "Determination of a new immunosuppressant, mycophenolate mofetil, and its active metabolite, mycophenolic acid, in rat and human body fluids by high-performance liquid chromatography," Journal of Chromatography B, vol. 654, pp. 249-256, 1994.

[7] K. Na-Bangchang, O. Supasyndh, T. Supaporn, V. Banmairuroi, and J. Karbwang, "Simple and sensitive high-performance liquid chromatographic method for the determination of mycophenolic acid in plasma," Journal of Chromatography B, vol. 738, no. 1, pp. 169-173, 2000.

[8] D. A. Saunders, “Author index vol. 690," Journal of Chromatography B, vol. 704, no. 1-2, pp. 379-382, 1997.

[9] K. Wiwattanawongsa, E. L. Heinzen, D. C. Kemp, R. E. Dupuis, and P. C. Smith, "Determination of mycophenolic acid and its phenol glucuronide metabolite in human plasma and urine by high-performance liquid chromatography," Journal of Chromatography B, vol. 763, no. 1-2, pp. 35-45, 2001.

[10] V. Srivatsan, A. K. Dasgupta, P. Kale et al., "Determination of mycophenolic acid in human plasma by high-performance liquid chromatography," Journal of Chromatography A, vol. 1031, no. 1-2, pp. 259-264, 2004.

[11] M. A. Barzoki, M. Rouini, K. Gholami, M. Lessan-Pezeshki, and S. Rezaee, "Determination of mycophenolic acid in human plasma by high-performance liquid chromatography," Daru, vol. 13, no. 3, pp. 120-126, 2005.

[12] S. Gopalakrishnan, E. Vadivei, P. Krishnaveni, and B. Jeyashree, "A novel reverse phase-HPLC method development and validation of Mycophenolate sodium-an immunosuppressant drug,"
Research Journal of Pharmaceutical, Biological and Chemical Sciences, vol. 1, no. 4, pp. 200-207, 2010.

[13] M. O. Benoit-Biancamano, P. Caron, É. Lévesque, R. Delage, F. Couture, and C. Guillemette, "Sensitive high-performance liquid chromatography-tandem mass spectrometry method for quantitative analysis of mycophenolic acid and its glucuronide metabolites in human plasma and urine," Journal of Chromatography B, vol. 858, no. 1-2, pp. 159-167, 2007.

[14] A. L. Rao, P. V. Srinivas, and J. V. L. N. S. Rao, "A new validated RP-HPLC method for the estimation of mycophenolate mofetil in pure and tablet dosage form," Journal of Pharmaceutical Research and Health Care, vol. 2, no. 3, pp. 266-269, 2010.

[15] H. Benech, S. Hascoet, V. Furlan, A. Pruvost, and A. Durrbach, "Development and validation of an LC/MS/MS assay for mycophenolic acid in human peripheral blood mononuclear cells," Journal of Chromatography B, vol. 853, no. 1-2, pp. 168-174, 2007.

[16] S. P. Verma, S. J. Gilani, I. Bala et al., "Validated, stability indicating HPTLC method for the determination of mycophenolate mofetil in human plasma," Current Analytical Chemistry, vol. 7, no. 3, pp. 216-219, 2011.

[17] S. Verma, H. Gupta, O. Alam, P. Mullick, N. Siddiqui, and S. A. Khan, "Spectrophotometric methods for the estimation of mycophenolate mofetil," Journal of Applied Spectroscopy, vol. 76, no. 6, pp. 876-882, 2010.

[18] F. E. Gainer and H. J. Wesselman, "GLC of mycophenolic acid and related compounds," Journal of Pharmaceutical Sciences, vol. 59, no. 8, pp. 1157-1159, 1970.

[19] S. K. Acharjya, A. Sahu, S. Das, P. Sagar, and M. M. Annapurna, "Spectrophotometric methods for the determination of mesalamine in bulk and pharmaceutical dosage forms," Journal of Pharmaceutical Research, vol. 1, no. 1, pp. 63-67, 2010.

[20] ICH Steering Committee, "Validation of analytical procedures: methodology," in Proceedings of the International Conference on Harmonization of Technical Requirements for Registration of Pharmaceuticals for Human Use, ICH Steering Committee, November 1996.

[21] A. H. Beckett and J. B. Stenlake, Practical Pharmaceutical Chemistry Edition, Part II, 4th edition, 2005. 

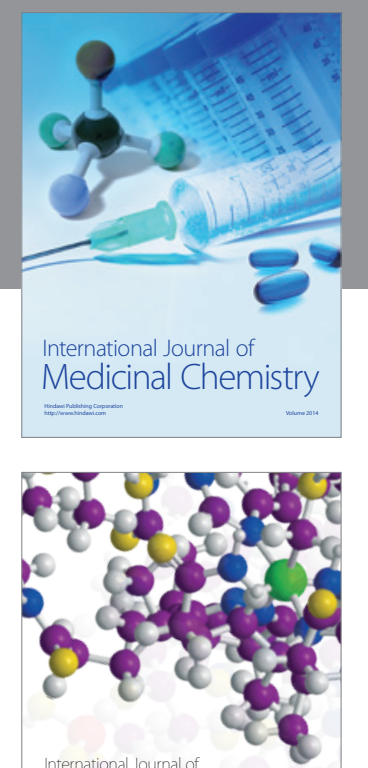

\section{Carbohydrate} Chemistry

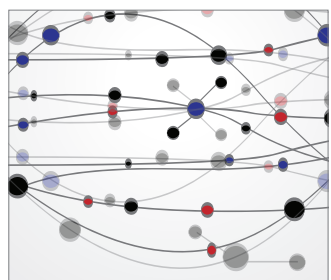

The Scientific World Journal
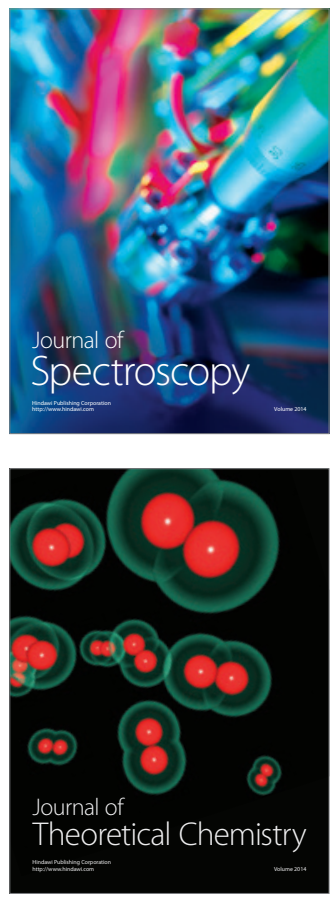
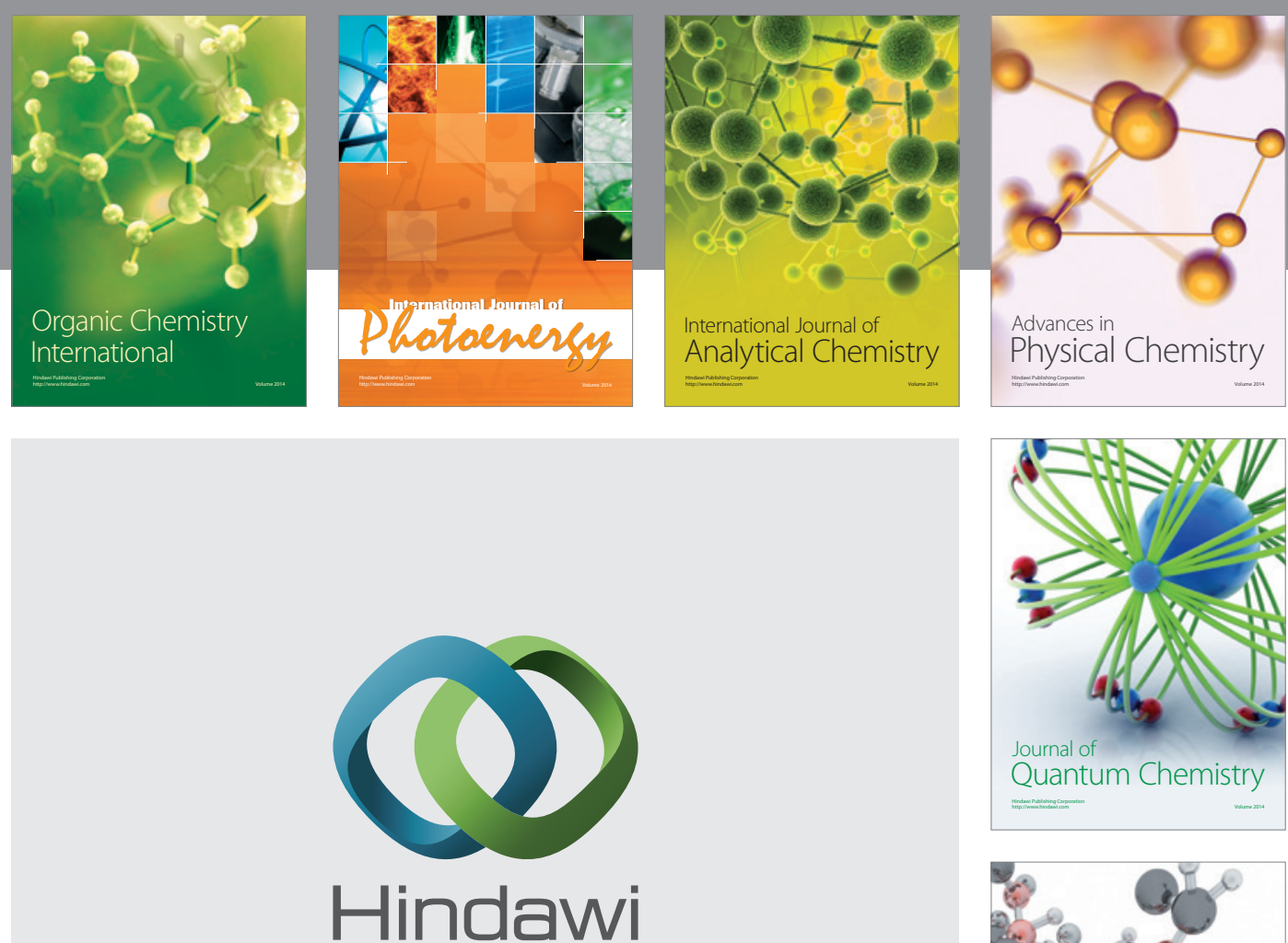

Submit your manuscripts at

http://www.hindawi.com

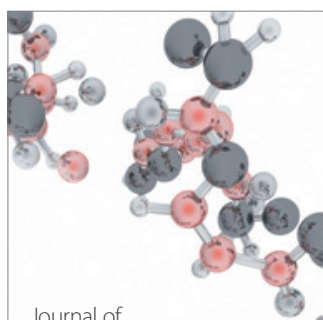

Analytical Methods

in Chemistry

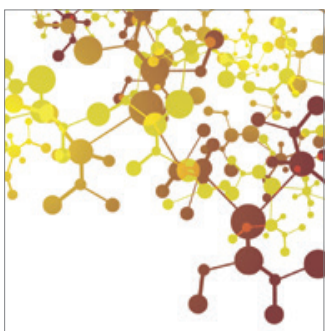

Journal of

Applied Chemistry

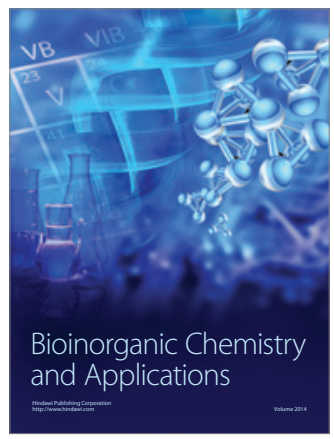

Inorganic Chemistry
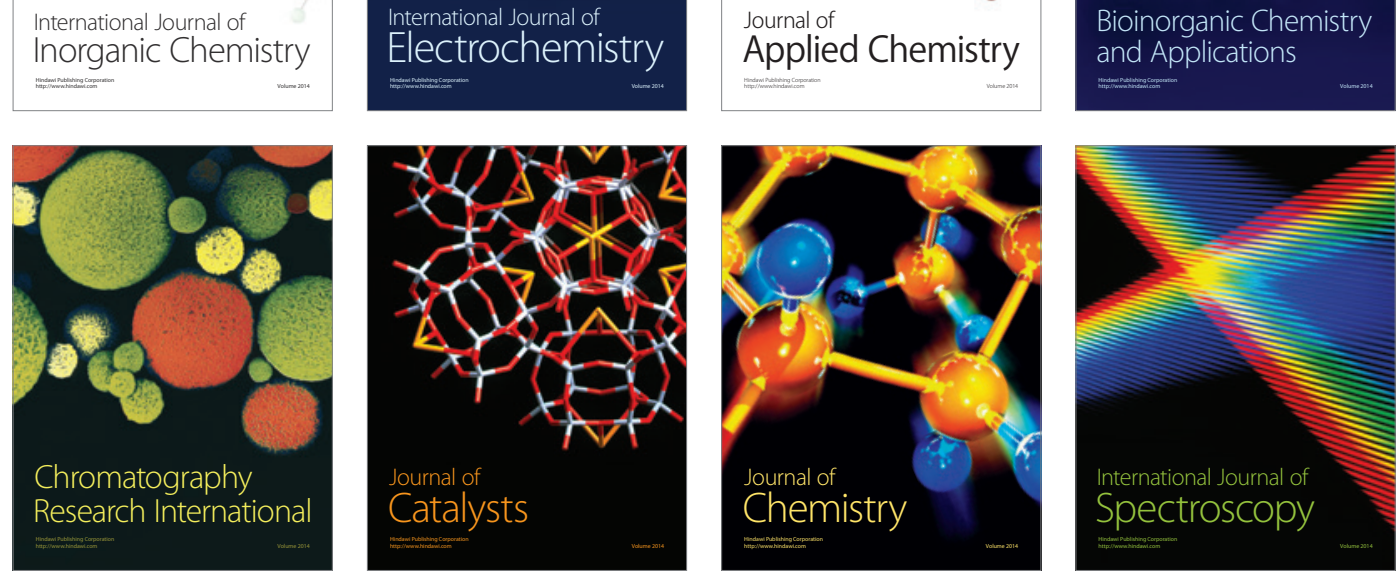